\title{
Population-level interventions targeting risk factors of diabetes and hypertension in South Africa: a document review
}

\author{
Jeannine Uwimana - Nicol ${ }^{1,2^{*}}$, Lynn Hendricks ${ }^{1,3}$ and Taryn Young ${ }^{1}$
}

\begin{abstract}
Background: South Africa bears an increasing burden of non-communicable diseases (NCDs), particularly diabetes, cardiovascular diseases, and cancer. The objective of this study was to identify which population-level interventions, implemented at the level of governmental or political jurisdictions only, targeting risk factors of diabetes and hypertension were included in policies in South Africa. We also looked at whether these have been implemented or not.
\end{abstract}

Methods: A review of relevant reports, journal articles, and policy documents was conducted. Documentation from government reports that contains information regarding the planning, implementation and evaluation of population-level interventions targeting diabetes and hypertension were considered, and various databases were searched. The identified population-level interventions were categorized as supportive policies, supportive programs and enabling environments according to the major risk factors of NCDs i.e., tobacco use, harmful consumption of alcohol, unhealthy diet/nutrition and physical inactivity, in accordance with the WHO 'Best buys'. A content document analysis was conducted.

Results: The source documents reviewed included Acts and laws, regulations, policy documents, strategic plans, case studies, government reports and editorials. South Africa has a plethora of policies and regulations targeting major risk factors for diabetes and hypertension implemented in line with WHO 'Best buys' since 1990. A total of 28 policies, legislations, strategic plans, and regulations were identified - 8 on tobacco use; 7 on harmful consumption of alcohol; 8 on unhealthy diet and 5 on physical inactivity - as well as 12 case studies, government reports and editorials. There is good progress in policy formulation in line with the 'Best buys'. However, there are some gaps in the implementation of these policies and programs.

Conclusion: Curbing the rising burden of NCDs requires comprehensive strategies which include population-level interventions targeting risk factors for diabetes and hypertension and effective implementation with robust evaluation to identify successes and ways to overcome challenges.

Keywords: Population-based interventions, Situation analysis, Diabetes, Hypertension, South Africa, Document review

\footnotetext{
* Correspondence: jeannine@sun.ac.za

${ }^{1}$ Centre for Evidence based Healthcare, Division of Epidemiology and

Biostatistics, Department of Global Health, Faculty of Medicine and Health

Sciences, Stellenbosch University, Cape Town, South Africa

${ }^{2}$ College of Medicine and Health Sciences, School of Public Health, University of Rwanda, Kigali, Rwanda

Full list of author information is available at the end of the article
}

(C) The Author(s). 2021 Open Access This article is licensed under a Creative Commons Attribution 4.0 International License, which permits use, sharing, adaptation, distribution and reproduction in any medium or format, as long as you give appropriate credit to the original author(s) and the source, provide a link to the Creative Commons licence, and indicate if changes were made. The images or other third party material in this article are included in the article's Creative Commons licence, unless indicated otherwise in a credit line to the material. If material is not included in the article's Creative Commons licence and your intended use is not permitted by statutory regulation or exceeds the permitted use, you will need to obtain permission directly from the copyright holder. To view a copy of this licence, visit http://creativecommons.org/licenses/by/4.0/ The Creative Commons Public Domain Dedication waiver (http://creativecommons.org/publicdomain/zero/1.0/) applies to the data made available in this article, unless otherwise stated in a credit line to the data. 


\section{Background}

According to the recent report from the World Health Organisation (WHO), non-communicable diseases (NCDs) are increasing globally and are the leading cause of premature deaths with an estimation of 41 million people dying from cardiovascular diseases, cancer, diabetes among other NCDs globally [1]. Low- and middleincome countries (LMICs) bear a high burden of NCDs with almost $70 \%$ of NCD related deaths [2]. The South African Demographic Health Survey (SADHS) cited in the national NCD Strategic plan (2020-2025) found that both women and men with diabetes are obese (24\% of women and $23 \%$ of men) [3]. In 2012, the prevalence of hypertension in South Africa was estimated at 35\% among people aged 15 years and above [4].

Cardiovascular disease (CVD) related risks such as hypertension is the key driver for morbidity and mortality world-wide, affecting approximately 1 billion people [5]. In Sub-Saharan Africa (SSA), it is estimated that 10 to 20 million people may have hypertension out of 650 million people [5]. Furthermore, a study conducted in four SSA countries including South Africa (SA) shows that the prevalence of hypertension was high (25.9\%) with almost half of the population unaware of having hypertension [6]. The economic burden of treating NCDs such as hypertension is quite high with an estimated cost of over 8 billion South African Rands annually [1]. The accumulated economic losses to SA's "gross domestic product between 2006 to 2015 due todiabetes, stroke and coronary heart disease were estimated at R26 billion" [3]. A study conducted by the World Economic Forum and the Harvard School of Public Health cited in the WHO report [7] shows that LMICs account for $83 \%$ of the NCDs (as measured by disability-adjusted life years). The burden of deaths and prolonged disability related to NCDs has a considerable economic impact on households, industries, and societies through healthcare related cost and via losses in income, productivity, and human capital [7]. To curtail such human and economic losses, specific interventions must be implemented to effectively tackle NCDs and their underlying risk factors.

There is a growing body of evidence that highlights both health and economic gains of interventions at population-level. These population-level interventions include interventions that promote low consumption of tobacco, alcohol, and salt; improved awareness of healthy lifestyle; increased excise taxes; and enhanced regulation [8]. The WHO has developed cost-effective interventions called 'Best buys' that can be delivered at primary healthcare level. These interventions focus on promoting health and preventing disease by targeting risk factors of NCDs through increasing tobacco taxes; restricting alcohol advertising; reduction of salt, sugar, and fat in food products; access to vaccine for cervical cancer for young girls; treating hypertension and diabetes among others [8]. The WHO argues that these interventions are likely to save " 10 million lives by 2025 and prevent 17 million strokes and heart attacks by 2030" [1].

Population-level interventions refer to policies or programs that aim at mitigating the distribution of health risk by addressing the underlying socio-economic, environmental, behavioral or cultural conditions in which people live and work [8]. Some interventions delivered in settings such as schools, and workplaces, can also be considered as population-level interventions. To accelerate national efforts to address NCDs, the World Health Assembly adopted a comprehensive global monitoring framework with 25 indicators and nine voluntary global targets for 2025 [2]. All WHO member states, of which SA is part of, through their ministries of health developed national NCD targets which informed the development and implementation of policies and interventions to be achieved through a 5-year SA national strategic plan (2012-2017). The latter is under review by various stakeholders in order to inform another 5 year strategic plan (2020-2025) [3]. Hence, it is imperative to take stock of the status of population-level interventions targeting risk factors of diabetes and hypertension, and NCDs at large at country level in order to inform the planned new NCDs strategic plan (2020-2025).

This document review forms part of a larger study on a "Situational analysis on population-level interventions targeting risk factors for diabetes and hypertension in SA". The purpose of this document review was to identify all population-level interventions targeting risk factors for diabetes and hypertension implemented in SA. It focuses on population-level interventions at the level of governmental or political jurisdictions only, e.g., cities, regions, countries. We also looked at whether current population-level interventions targeting NCDs with specific emphasis on diabetes and hypertension are in line with the recommended WHO 'Best buys', and their implementation process (i.e. feasibility, acceptability, process and impact evaluation).

\section{Methods}

This study used a document review methodology, which is one of the research methods commonly used in the field of Health Policy Analysis (HPA) [9]. The Centre for Diseases and Control defines document review as a research method whereby data is gathered from existing documents [10]. Kayesa and Shung-King in their systematic review argue that document review is a systematic way of reviewing existing documents (accessible online or grey literature) in order to understand and measure policy actions against what was stated or planned for [11]. Although there are other research methods 
employed in HPA, document review is the most convenient method used in LMICs [9].

A review of relevant reports, journal articles, or policy documents was conducted at the end of 2019. Documentation from government reports that contained information on the planning, implementation and evaluation of population-level interventions targeting diabetes and hypertension, and NCDs in general were considered. The WHO 'Best buys' [8] was used as framework to conduct the document review. These population-based interventions were grouped into three categories namely supportive policies, programs and enabling environments. The WHO Global Strategy for Diet, Physical Activity, and Health (DPAS) [12] defines these interventions as follow:

- Supportive Policies refer to fiscal, legislative and regulatory measures that can target risk factors for diabetes and hypertension. These policies could be trade and agricultural policies that promote healthy diets.

- Supportive Programs refer to national, district or community-based programs that reach people where they live, study, work, and play. These programs could be government or non-governmental health facilities offering diet and physical activity counselling for obesity or diabetes.

- Supportive Environment / enabling environments refer to activities tailored to influence the creation of environments in which healthy choices are the easier option for people. These could include cycling lanes, public gyms, etc. to promote physical activities.

Databases used to run the search included Pubmed, Ebscohost, Google scholar, Scopus, and the Cochrane database. Search terms included diabetes/hypertension/physical activity/nutrition/alcohol consumption/tobacco smoking/ programs/interventions/South Africa (Additional file 1). There was no restriction of date and language applied to the search. An excel spreadsheet was designed to extract relevant information relating to what interventions have been implemented, their coverage, target audience and if they have been any process or impact evaluation of the identified interventions. Data extraction was done in duplicate (JN and LH).

The identified population-level interventions were grouped in line with WHO 'Best buys', and content analysis was conducted according to the major risk factors of NCDs i.e., tobacco use, harmful consumption of alcohol, unhealthy diet/nutrition and physical inactivity'. Obesity was considered as risk factor for both diabetes and hypertension, and identified population-level interventions targeting obesity were related to unhealthy diet and physical inactivity. Progress of the implementation of WHO 'Best buys' was done by checking whether the formulated supportive policies are in line with WHO 'Best buys' (content wise).

\section{Results \\ Description of reviewed documents}

A total of 2387 records were retrieved (published and grey literature) and 42 documents were selected and reviewed (Fig. 1). Documents reviewed included 28 policies, legislations, strategic plans, and regulations (Table 1) and 14 case studies, government reports and editorials (Table 2). These were grouped into two categories namely Supportive Policy interventions; and Supportive Programs and Enabling environments given that the interventions related to 'Enabling environments' were few and linked to programs.

There is a plethora of available policies and regulations targeting major risk factors for diabetes and hypertension that have been in existence since 1990. These major risk factors include unhealthy diet, tobacco use, harmful alcohol use and physical inactivity; and were based on the WHO 'Best buys' [8].

There were 8 policies on tobacco use (smoking); 7 policies on harmful consumption of alcohol; 8 policies on unhealthy diet which include the National strategic plan for prevention and control of obesity and 5 policies on physical inactivity (Table 1 ). Table 3 provides a summary of the key strategies included in these policies and regulations.

Supportive programs considered in this review are current programs targeting risk factors for diabetes and hypertension in line with the WHO 'Best buys', at governmental jurisdictions level (i.e., Cities, Provincial or National level). South Africa has several comprehensive programs that target a the four major risk factors and most of these programs focus on unhealthy diet, tobacco use and physical inactivity.

However, many of these programs have not been implemented across SA and evaluated to determine the impact on the occurrence and control of diabetes and hypertension, and NCDs prevention at large. Overall, 13 supportive programs were identified as currently implemented in SA, of which 6 focus on unhealthy diet [16, 18-20, 22, 26]; 3 on tobacco smoking [27-29] and 4 on physical inactivity [24, 30-32]. Table 4 summarises the programs, the risk factors, description, and findings from studies. Table 5 illustrate the progress of implementation of WHO 'Best buys' in South Africa to date.

\section{Implementation and impact of population-level interventions in South Africa}

Ndinda and Hongoro' report [16] on the analysis of NCDs prevention policies in SA highlights that the 


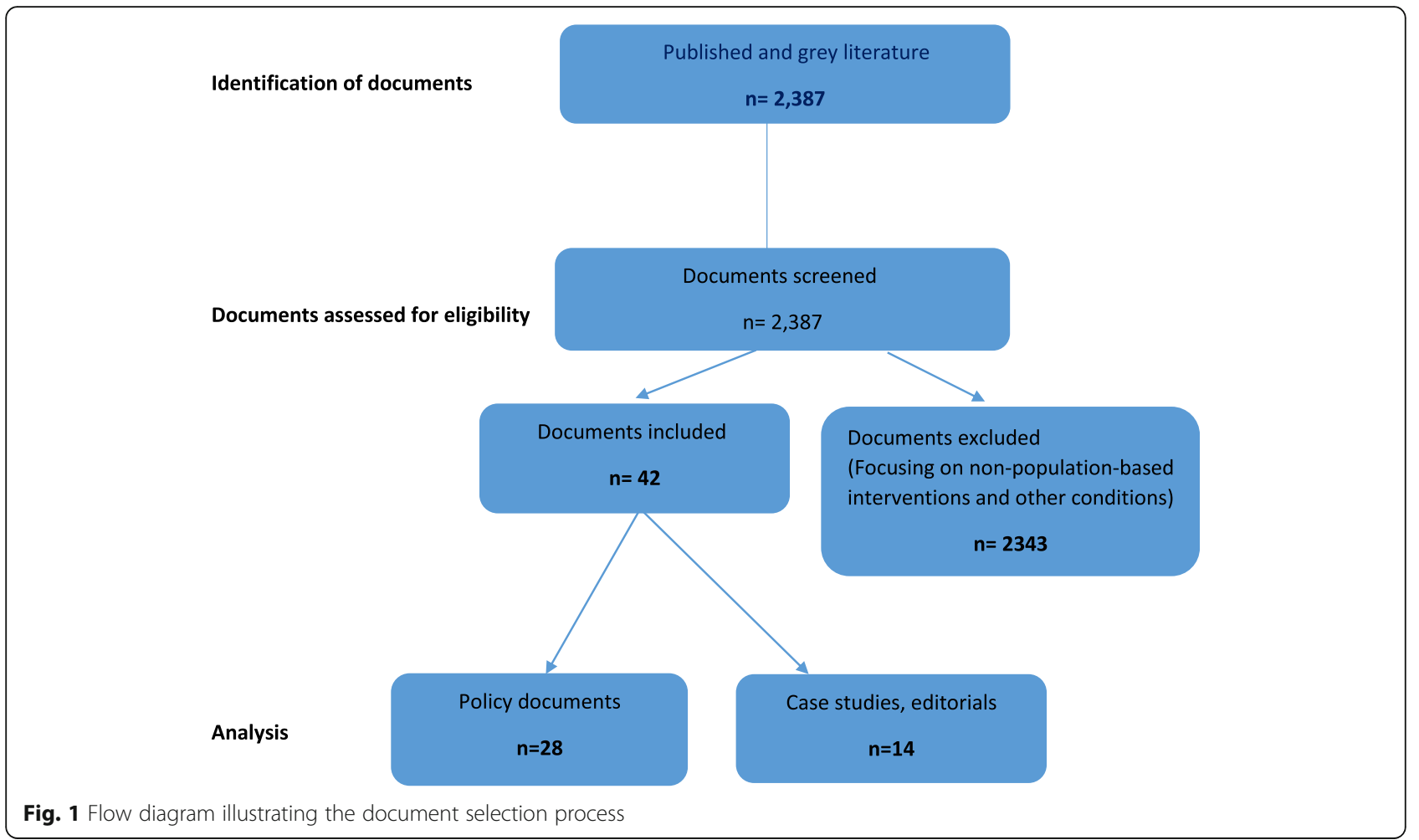

implementation of initial regulations on tobacco products contributed to reduction in tobacco smoking by 26\% in the period between 1993 and 2000. This reduction in smoking was mainly seen among young people aged 16-24 indicating a decline from 24 to $19 \%$ in the same period [24]. However, the rate of smoking has been stagnant since 2010. However, there is no available data that explain the reasons for stagnation in smoking among South Africans.

The annual tax increase on tobacco products has the potential to discourage people who might want to adopt smoking but also to incentivise those who have been trying to quit [16]. According to Linegar and Walbeek [24], in 2018 the excise tax on tobacco products in SA was at $52 \%$ below the recommended WHO Framework Convention on Tobacco Control (FCTC). Hence, the NDoH has revised its regulations to enforce plain packaging and clean air regulations, regulate e-cigarettes, and increase taxes to revitalise efforts to reduce tobacco use [16].

In 2010, the WHO estimated an average annual per capita consumption of alcohol for SA (persons over 15 years of age) as $11 \mathrm{l}$; and the numbers of heavy episodic drinkers as $26 \%$. The policies on harmful alcohol use focus more on the regulation of alcohol production and distribution which address mainly trade and industry concerns than prevention of NCDs [16]. They reported that re-enforcement of these policies is lacking and thus the difficulty to measure the impact of such policies/regulations on reduction of alcohol consumption.
Unhealthy food environments, including limited access to and affordable healthy food contribute to consumption of these unhealthy food. Healthier food options are relatively costly ranging from 10 and $60 \%$ more compared to the prices of unhealthy foods at retail outlets [3]. Drawing on best practice from high income countries in preventing and controlling NCDs by targeting unhealthy diets, the South African government introduced taxation on sugarsweetened beverages (SSBs) from 1st April 2017 [16]. Beverages such as soft drinks, fruit juices, energy drinks and vitamin water were levied [17].

Stacey et al. [33] in their study highlights that no price increase among non-taxed beverages and that there was a significant price increase for carbonated drinks. The latter was identified as the largest taxed product category of SSBS. An economic evaluation by Saxena et al. [23] found that "10\% SSB tax increase would avert an estimated 8000 Type 2 Diabetes Mellitus (T2DM)-related premature deaths over 20 years, with most deaths averted among the third- and fourth-income quintiles". The same study estimated that "32 000 of T2DM related cases of catastrophic expenditures and 12000 cases of poverty would be averted" [23]. However, there are no accessible data at population-level that could determine the impact of SSB taxation on the occurrence of diabetes.

In 2011, the former Minister of Health Dr. Mostoledi pioneered the legislation for salt reduction in food products and encouraging South Africans to be conscious of 


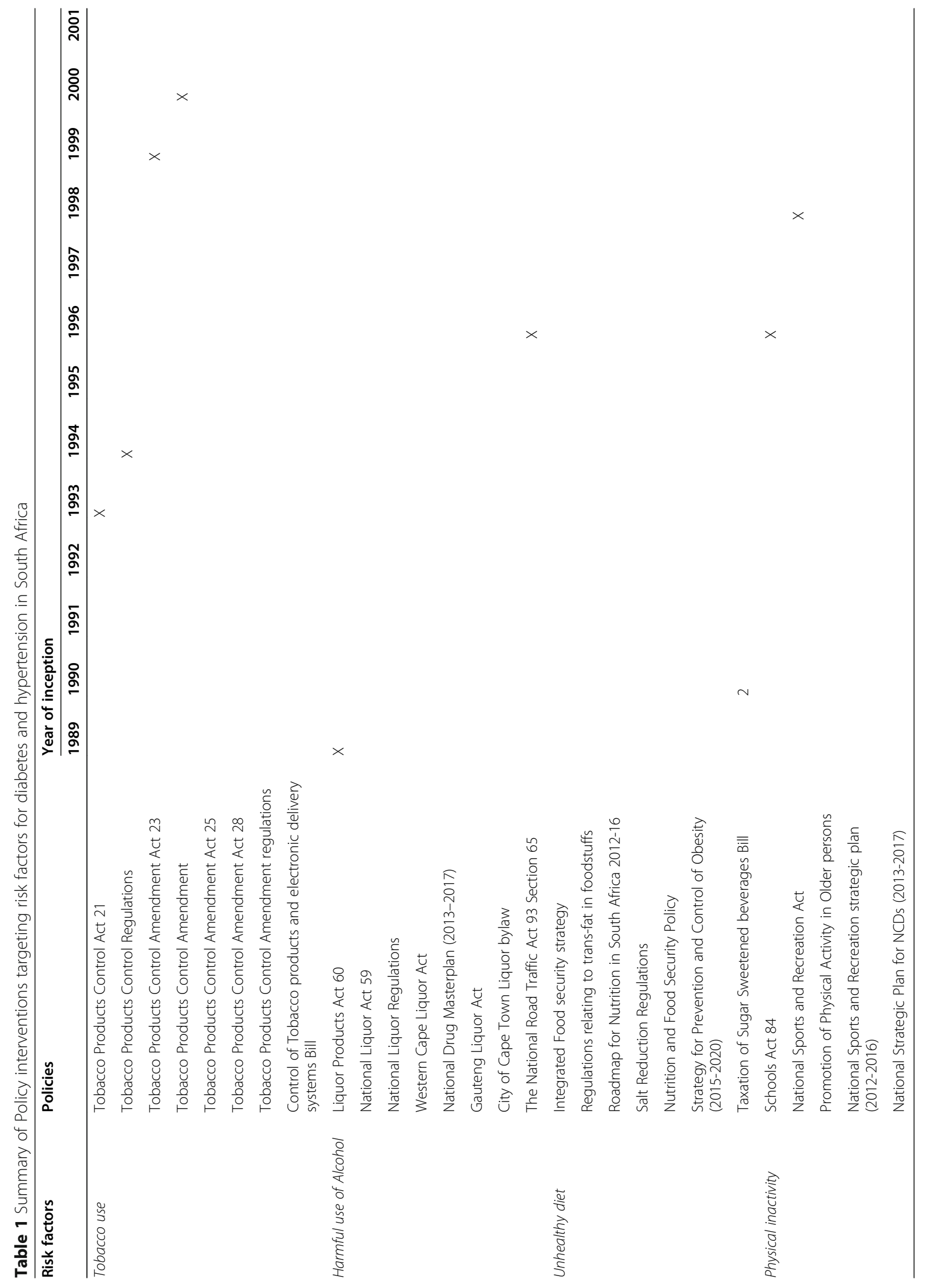




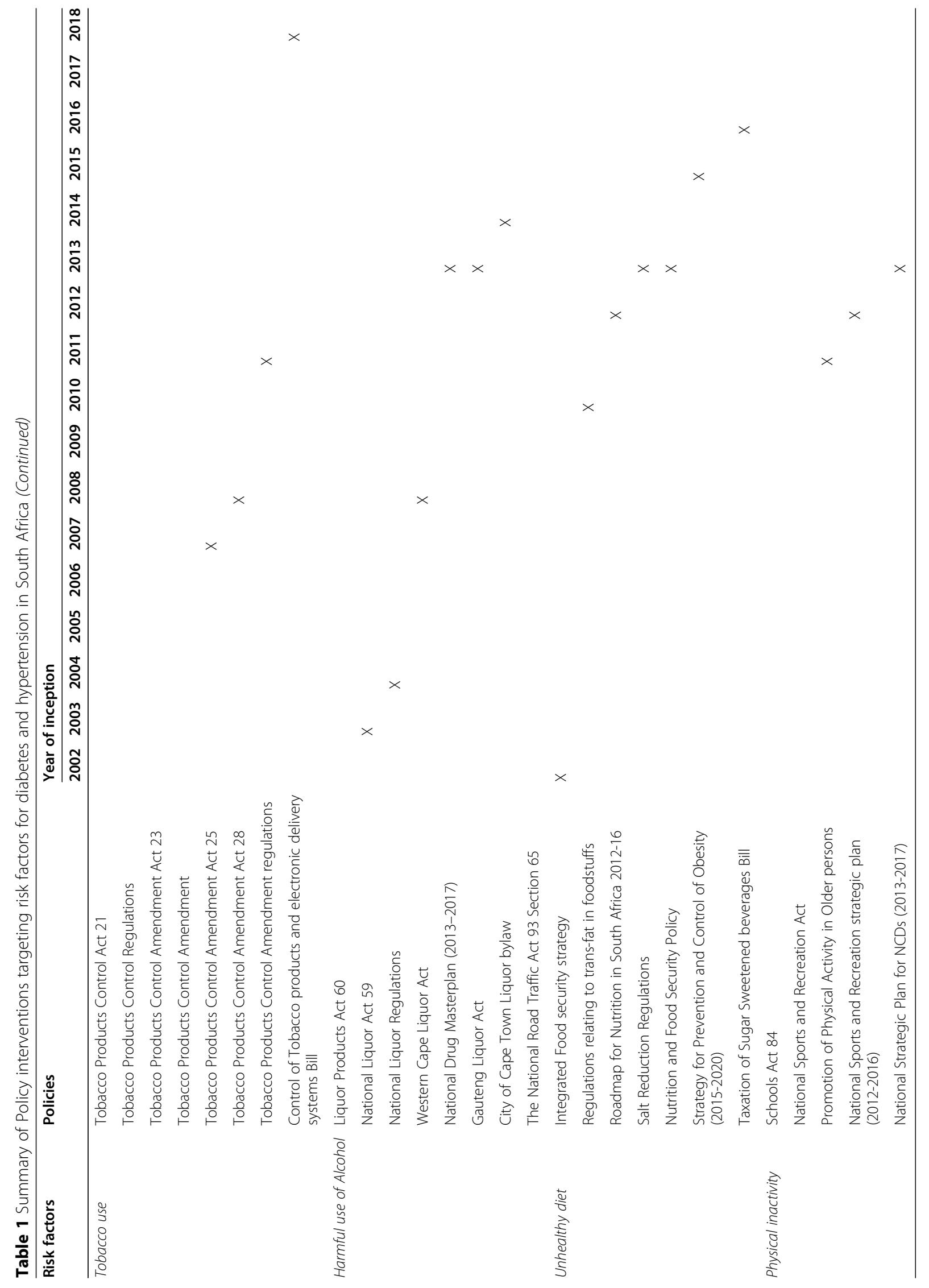


Table 2 Summary of case studies, government documents and editorials ( $n=12$ )

\section{Title}

How will South Africa's mandatory salt reduction policy affect its salt iodisation program? A cross-sectional analysis from the WHO-SAGE Wave 2 Salt and Tobacco study

The evolution of non-communicable diseases policies in post-apartheid South Africa

A hidden menace: Cardiovascular disease in South Africa and the costs of an inadequate policy response

Analysis of non-communicable diseases prevention policies in Africa (ANPPA) - A case study of South Africa. A technical research report developed for the African Population \& Health Research Centre (APHRC)

South African Health Review - Diet-related non-communicable diseases in South Africa: determinants and policy responses

Eating Better for Less: A National Discount Program for Healthy Food Purchases in South Africa

National School Nutrition Program South Africa.

Department of Agriculture of South Africa 2012: Integrated food security strategy for South Africa

South Africa's salt reduction strategy: Are we on track, and what lies ahead?

Evaluation of a Mass-Media Campaign to Increase the Awareness of the Need to Reduce Discretionary Salt Use in the South African Population

Sugar-based beverage taxes and beverage prices: Evidence from South Africa's Health Promotion Levy

The distributional impact of taxing sugar-sweetened beverages: Findings from an extended cost-effectiveness analysis in South Africa

The effect of excise tax increases on cigarette prices in South Africa

Support for alcohol policies from drinkers in the City of Tshwane, South Africa: Data from the International Alcohol Control study

Western Cape on Wellness (WOW!) Healthy Lifestyles Initiative Design and Outcome Evaluation of Phase 1 Pilot Implementation

\section{Type of paper}

Citation

Case study - cross sectional study

Case study - Policy review through documents review supplemented by qualitative data

Case study - Policy review undertaking document review

Case study - Technical report

Case study - Policy review undertaking document review

Case study- cross- sectional study

Government Report

Government Report

Editorial

Case study - Cross sectional survey

Case study - Process evaluation

Case study - Economic evaluation

Case study - Economic evaluation

Case study - Cross sectional survey

Case study - Evaluation study

Table 3 Key strategies included in the policies and regulations

\begin{tabular}{|c|c|}
\hline Risk factor & Strategies \\
\hline Tobacco use & $\begin{array}{l}\text { Annual tax increases } \\
\text { Advertisements of tobacco products banned. } \\
\text { Tobacco smoking in public buildings banned. } \\
\text { Allocation of smoke-free zone } \\
\text { Health information and warnings }\end{array}$ \\
\hline Unhealthy diet & $\begin{array}{l}\text { Tax sugar-sweetened beverages } \\
\text { Reduced salt intake } \\
\text { The trans-fat content of any oils and fats cannot exceed two grams per } 100 \mathrm{~g} \text {, according to } \\
\text { South African legislation. Products with higher trans-fats levels are prohibited from entering } \\
\text { or being sold in the country }\end{array}$ \\
\hline Harmful alcohol use & $\begin{array}{l}\text { Zero tolerance with regards to "drink and driving". } \\
\text { Taxation } \\
\text { Normalisation of the previously illegal drinking houses (Sheebens) } \\
\text { Regulating drinking hours } \\
\text { Change of the legal age for drinking from } 18 \text { years to } 21 \text { years. } \\
\text { Banning alcohol advertising }\end{array}$ \\
\hline Physical inactivity & $\begin{array}{l}\text { Public awareness of physical activity } \\
\text { Cycling lanes on major public roads }\end{array}$ \\
\hline
\end{tabular}




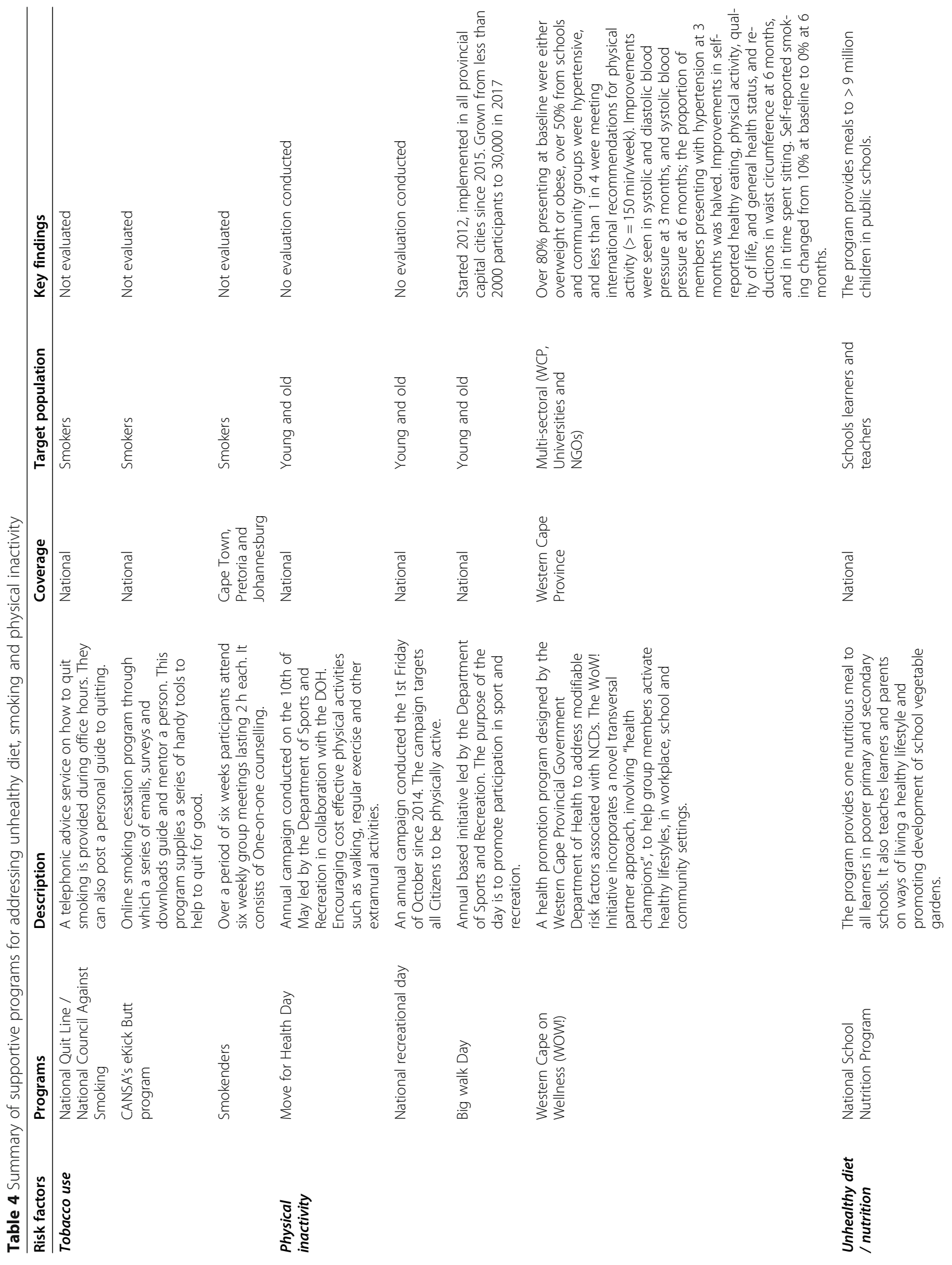







Table 5 Implementation of "WHO Best Buy' Interventions in South Africa to date

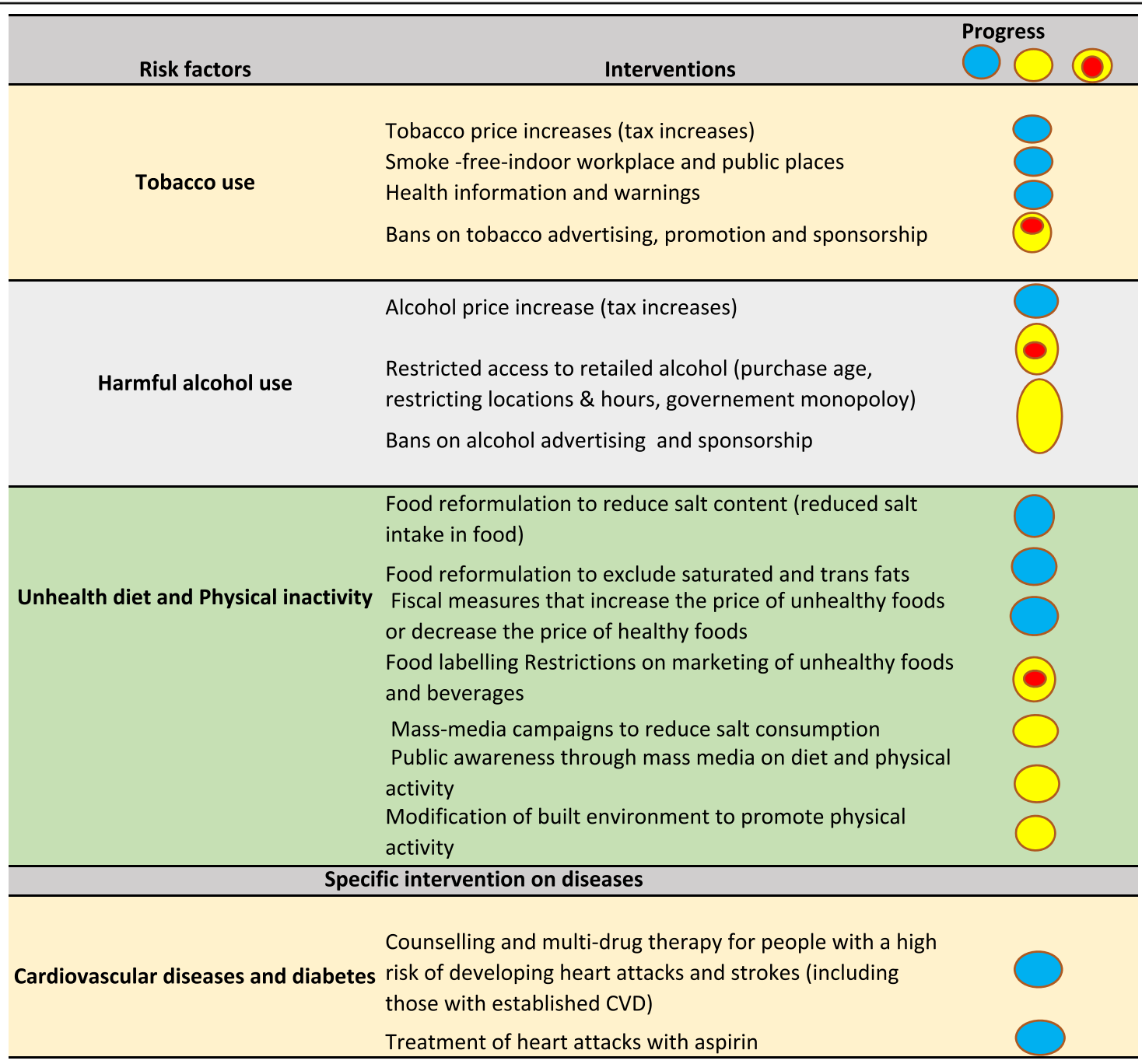

Fully implemented Partially implemented In progress/Inadequate

their salt intake. Studies show that reformulation of salt in food products such as bread has the potential of saving 6500 lives annually [16]. By 2013, the salt reduction regulations were adopted as an intervention targeting hypertension [14]. The NDoH granted a 3-year period to food industries to tease out ways of reformulating and producing lower salt products acceptable to consumers. It has been estimated that SA's salt reduction policy will reduce $11 \%$ of deaths from heart disease per year and save the government approximately ZAR 713 million per year in healthcare costs [21]. At the individual level, healthcare cost savings could prevent 2000 households being pushed into poverty [21].

In addition to legislation, Webster et al. [21] highlights some priority areas for continued action on salt reduction - active monitoring of formal and informal food industry, improved awareness on discretionary salt intake and addressing behaviour change and other social determinants of health.

Furthermore, a study conducted by the WHO-SAGE Wave 2 Salt \& Tobacco highlights the need to closely monitor the iodine status of populations as the measures of salt reduction are implemented [13].

The Bill on Trans-fatty acid [34] focused on reducing trans-fats content in certain processed and prepared foods currently for sale in SA, because trans-fatty acids significantly increase the risk of CVD. The trans-fat content of any oils and fats cannot exceed 2 grams per 100 g, according to South African legislation [34]. Products with higher trans-fats levels are prohibited from entering 
or being sold in the country. The legislation covers any oils and fats "either alone or as processed foods, which are intended for human consumption or assumed to be intended for human consumption, in the retail trade, catering businesses, restaurants and institutions" [34]. Manufacturers and retailers were given 6 months to comply and reduce the trans-fat content of their products to the required 2 g per 100" [16].

Currently, the guidelines on Advertising and Labelling of Foodstuffs (under revision), which were promulgated under the Foodstuffs, Cosmetics and Disinfectants Act, 1972 (Act 54 of 1972) do not address the labelling of trans fats, especially industrially produced trans fatty acids [15]. The NDoH has been monitoring the labels of food products and the food industry has complied to some extent. However, there is no systematic assessment on how well industries have complied with food labelling and whether food libelling has influenced behaviour change or consumer patterns of certain food [14]. Therefore, empirical studies are needed to determine the impact of food labelling interventions on consumers' behaviour.

Other relevant national level-policies that shape provincial and community-level actions impacting food environments are the Integrated Food Security Strategy, the Integrated Nutrition Programme, the National School Nutrition Programme, and the National Policy on Food and Nutrition Security. However, collectively these policies frame food insecurity as they do not take account of environmental issues or spatial contexts around access and affordability to nutritious food [17]. The SA sports policy was formulated in 1998 with a focus on transformation of sport and racial representation in competitive sport. The National Sport and Recreation Strategic Plan 2012 [35] lists appropriate objectives to tackling physical inactivity in the general population, aiming for a $10 \%$ increase in the uptake of physical activity at population-level by 2020 . However, there is a lack of interventions geared to an enabling environment countrywide as well as monitoring and evaluation (M\&E) systems to measure the impact of these interventions [16].

\section{Challenges for the implementationof population-level interventions in South Africa}

Limited funding allocated to provinces and NGOs was identified as the main hindrance to effective implementation of population-level interventions as well as lack of strong monitoring and evaluation systems at grassroots level in order to determine the impact of these interventions [17]. Most of supportive programs and enabling environment activities are mainly implemented at provincial level by NGOs while government structures focus on policy formulation.
Also, there is a conflict of interest between the national trade and investment policy vis-a-vis the national health policy whereby trade and foreign direct investment have a tendency of promoting the influx of large amounts of processed foods and sugary beverages, giving a certain level of power to fast food companies like McDonalds and Burger King [17].

Finally, lack of inter-sectoral approaches in implementing these population-level interventions targeting risk factors of diabetes and hypertension has been identified as another impediment to effective policy implementation $(16 ; 29)$.

\section{Discussion}

Both hypertension and diabetes, are major contributors to morbidity and mortality worldwide [36]. In 2013, the SA government committed to reduce by at least $25 \%$ the relative premature mortality (under 60 years of age) from NCDs by 2020 through its strategic plan for NCDs [37]. The findings of this document review show that the SA government has made progress with policy formulation and implementation of population-level interventions targeting diabetes and hypertension, and NCDs prevention at large as recommended by WHO 'Best buys'. The findings of this review echoes the findings from the WHO report on the NCDs progress monitor [1].

Supportive programs identified in this document review focus on unhealthy diet, tobacco use and physical inactivity. The coverage of these supportive programs ranged from national, provincial to city level. There are fewer supportive programs targeting harmful consumption of alcohol. This could be due to the potential economic conflicts between health gains vs economic gains which might result in opposition from industries as it has been reported in other African countries [38, 39].

The findings of this document review also highlight that despite interventions addressing tobacco consumption such as taxation, a ban on smoking in public spaces and cigarette advertising, and written warnings on cigarette packaging, there is a gap in policy legislation when it comes to smoking in work areas where nonpublic servants such as domestic workers, gardeners and others operate [17]. Similarly to other SSA countries [38], SA is still lagging behind in achieving the implementation of the full WHO FCTC. This could be due to the inherent conflicts of priorities between government departments such as NDoH and department of Trade and Industry on regulations related the economic gains $[39,40]$. Although SA is one of the few countries in LMICs with many supportive policies and programs on NCDs including diabetes and hypertension in line of WHO 'Best buys', the extent of implementation and their impact on the overall NCDs related outcomes is a big question that still needs to be answered. 
Lack of multi-sectoral approaches in LMICs is a contributing factor to non-effective implementation of supportive interventions [39]. This has been echoed by various researchers in LMICs [39, 41, 42]. Hence, there is a need for multi-sectoral and bottom-up approaches for effective implementation of population-level interventions on NCDs. Achieving global and national targets for physical activity, requires a multi-sectoral collaboration between transport, urban planning, recreation, and sports and education departments as well as the South African policy services (SAPS) to create safe environments that are conducive to physical activity for all age groups [43]. A study conducted in Ghana and Cameroon [44] shows that there have been a number of programs striving to create enabling environments to promote physical activities such as creation of fitness clubs, community works led by church groups but these were mainly covering a particular class of the society - urban areas and middle income groups.

Supportive environment interventions targeting risk factors for diabetes and hypertension implemented at country level seems not to be well documented. This could be due to the fact that most of supportive environment activities are implemented at community and individual level with little or non-existence of systematic documentation of such programs [45]. In addition, documentation on the process of implementation and evaluation $(\mathrm{M} \& \mathrm{E})$ is missing in the literature. This has been observed in other LMICs such as Kenya, Togo, Cameron, Malawi and Iran where the implementation of WHO 'Best buys' have been largely focusing on policy and programs than creating enabling environments that target risk factors related to diabetes and hypertension [39, 41]. Lack of M\&E plans for population-level interventions and for NCDs in general have been reported in other SSA countries such as Zambia, Kenya, Malawi and Cameroon [38, 39].

The findings of our document review show that limited funding for population-level interventions and NCDs prevention policies and programs has been one of the contributing factors to poor implementation of these policies and programs. Bourdeaux and colleagues argue that limited funds for NCDs prevention and control is due to the fact most LMICs countries get their funding from NGOs [39]. Consequently, limited funding for the implementation of NCDs strategic plans has a direct impact on establishment of M\&E systems to assess the effectiveness and impact of the policies and programs emanating from these NCDs strategic plans.

\section{Study strengths and limitations}

Document reviews are commonly used in the field of HPA $[9,11]$, particularly in LMICs, as is the most convenient approach to understand the measure what policy actions against what was stated and planned. Key stakeholders involved with development and formulation of NCDs policies at national and provincial levels, helped us in accessing some of the policy documents that were not in the public domain and assisted in inclusion of document to review [11]. We used a comprehensive approach to identify relevant documents and to extract data in a standardised manner. The data extraction of included studies was based on the WHO 'Best buys' which provided a focus lens for taking stock of population-level interventions that have been proved to be effective. However, not all documents were in the public domain and accessible. The findings of this study are limited to what has been documented. It's important to note that the findings of this document review could be enhanced through input from key role players on policy implementation process, related successes and challenges. Also, there is a scarcity of population-level data and empirical studies that assess the effectiveness and the impact of supportive policies, programs and enabling environment targeting diabetes and hypertension on the prevalence and occurrence of diabetes and hypertension in South Africa. Hence, there is a need for future studies to determine the impact of WHO 'Best buys' interventions on prevention and control of NCDs in general.

\section{Conclusion}

South Africa has a growing burden of NCDs particularly diabetes and hypertension. Mortality and prolonged disability associated with NCDs have a considerable economic impact on households, industries and societies, both via the consumption of health services and via losses in income, productivity and capital formation. South Africa has done relatively well in including WHO 'Best buys' interventions in policies and with implementation. As the National Department of Health is revising the NCDs strategic plan (2020-2025), a critical engagement between inter-government departments and private sector as well as the public in formulating and implementing supportive policies, programs and enabling environments is paramount. Empirical studies are needed to determine the impact of population-level interventions on prevention and control of hypertension and diabetes, and other NCDs.

\section{Supplementary Information}

The online version contains supplementary material available at https://doi. org/10.1186/s12889-021-11910-6.

Additional file 1. Pubmed search strategy.

\section{Acknowledgements}

We would like to thank Prof. Melvyn Freeman - former director of NCDs Directorate Unit and Mrs. Sandhya Singh - Acting director, NCDs Directorate Unit at the National Department of Health, South Africa for sharing policy 
documents and reports related to NCDs. Also, would like to acknowledge the assistance of Prof. Celeste Naude from Centre for Evidence-based Healthcare, Department of Global Health, Faculty of Medicine and Health Sciences at Stellenbosch University for sharing document and links related to Nutrition and Diets.

\section{Authors' contributions}

JUN developed and conceptualised the paper, conducted the search, screening of eligible documents and developed a data extraction tool. JUN extracted the data and analysed and wrote the manuscript. TY contributed to the conceptualisation of the paper, analysis and writing process with critical commentary. LH assisted with data extraction and provided comments on drafts. All authors have read and approved the manuscript.

\section{Authors' information}

JUN is a senior researcher at the Centre for Evidence-based Healthcare (CEBHC), Division of Epidemiology and Biostatistics, Department of Global Health, Stellenbosch University. LH is teaching facilitator and PhD candidate at the CEBHC, Division of Epidemiology and Biostatistics, Department of Global Health, Stellenbosch University and the Social Research Methods Group, KU Leuven. TY is the Director of the CEBHC and Head of Division of Epidemiology and Biostatistics, Department of Global Health, Stellenbosch University.

\section{Funding}

The review work was supported by the funding from the Collaboration for Evidence-based Healthcare and Public Health in Africa (CEBHA+) project which is funded by the German Federal Ministry of Education and Research (BMBF) as part of the Research Networks for Health Innovation in Sub-Saharan Africa Funding Initiative. The funder doesn't have any role in the review process.

\section{Availability of data and materials}

All data relevant to the study are included in the article or uploaded as supplementary information.

\section{Declarations}

\section{Ethics approval and consent to participate} Not Applicable.

\section{Consent for publication}

Not Applicable.

\section{Competing interests}

The authors declare that they have no competing interests.

\section{Author details}

${ }^{1}$ Centre for Evidence based Healthcare, Division of Epidemiology and Biostatistics, Department of Global Health, Faculty of Medicine and Health Sciences, Stellenbosch University, Cape Town, South Africa. ${ }^{2}$ College of Medicine and Health Sciences, School of Public Health, University of Rwanda, Kigali, Rwanda. ${ }^{3}$ Social, Methodological, Innovative, Kreative, Centre for Sociological Research, Faculty of Social Sciences, Katholieke Universiteit Leuven, Leuven, Belgium.

Received: 23 April 2021 Accepted: 24 September 2021

Published online: 14 December 2021

\section{References}

1. The World Health Organisation. Non-communicable diseases. Noncommunicable diseases progress monitor 2020. Geneva: World Health Organization; 2020

2. World Health Organization. Global Status Report On Noncommunicable Diseases 2014. 2014

3. National Department of Health. National strategic plan for the prevention and control of non-communicable diseases 2020-2025 (draft document). Pretoria: 28 October 2019 Table of contents; 2020.

4. Berry KM, Parker WA, McHiza ZJ, Sewpaul R, Labadarios D, Rosen S, et al. Quantifying unmet need for hypertension care in South Africa through care cascade: Evidence from the SANHANES, 2011-2012. BMJ Global Health. 2017;2(3):e000348. https://doi.org/10.1136/bmjgh-2017-000348 BMJ Publishing Group.

5. Guwatudde D, Nankya-Mutyoba J, Kalyesubula R, Laurence C, Adebamowo C, Ajayi IO, et al. The burden of hypertension in sub-Saharan Africa: a fourcountry cross sectional study. BMC Public Health. 2015;15(1):1211. https:// doi.org/10.1186/s12889-015-2546-Z

6. Ataklte F, Erqou S, Kaptoge S, Taye B, Echouffo-Tcheugui JB, Kengne AP. Burden of undiagnosed hypertension in sub-saharan africa: a systematic review and meta-analysis. Hypertension. 2015;65(2):291-8. https://doi.org/1 0.1161/HYPERTENSIONAHA.114.04394.

7. World Health Organization. From burden to " best buys ": reducing the economic impact of non-communicable diseases in low- and middleincome countries. Geneva: World Health Organisation; 2011.

8. WHO. "Best buys" and other recommended interventions for the prevention and control of noncommunicable diseases. World Health Organ. 2017;17(9): 28.

9. Gilson L, Raphaely N. The terrain of health policy analysis in low and middle income countries: a review of published literature 1994-2007. Health Policy Plan. 2008;23(5):294-307. https://doi.org/10.1093/heapol/czn019.

10. CDC report. Evaluation briefs data collection methods for evaluation: document review. Eval Briefs. 2018;13(18):1-2.

11. Kayesa NK, Shung-King M. The role of document analysis in health policy analysis studies in low and middle-income countries: lessons for HPA researchers from a qualitative systematic review. Health Policy Open. 2021;2: 100024. https://doi.org/10.1016/j.hpopen.2020.100024.

12. World Health Organisation (WHO). WHO global strategy on diet, physical activity and health: a framework to monitor and evaluate implementation. 2008 [cited 2021 July 6]. Available from: https://www.who.int/dietphysicala ctivity/M\&E-2008-web.pdf

13. Webster J, Crickmore C, Charlton K, Steyn KW-VE. And NP. South Africa's salt reduction strategy: are we on track, and what lies ahead? South Afr Med J. 2017;107(1):20-1. https://doi.org/10.7196/SAMJ.2016.v107.11.12120.

14. Saxena A, Stacey N, Puech PDR, Mudara C, Hofman K, Verguet S. The distributional impact of taxing sugar-sweetened beverages: findings from an extended cost-effectiveness analysis in South Africa. BMJ Glob Health. 2019:4(4). https://doi.org/10.1136/bmjgh-2018-001317.

15. National Department of Health. Bill on Trans-fatty Acid 2009. 2009.

16. An R, Patel D, Segal D, Sturm R. Eating better for less: a national discount program for healthy food purchases in South Africa. Am J Health Behav. 2013;37(1):56-61. https://doi.org/10.5993/AJHB.37.1.6.

17. Linegar DJ, Van Walbeek C. The effect of excise tax increases on cigarette prices in South Africa. Tob Control. 2018;27(1):65-71. https://doi.org/10.113 6/tobaccocontrol-2016-053340.

18. Africa D of A of S. Integrated food security strategy for South Africa. 2002.

19. Western Cape Department of Health. Western Cape on Wellness (WOW!) Healthy lifestyles initiative design and outcome evaluation of phase 1 pilot implementation. Cape Town: Western Cape Department of Health; 2017.

20. Department of Education of South Africa. National School Nutrition Programme (NSNP) Annual Report. 2012.

21. Ndinda C, Ndhlovu TP, Juma P, Asiki G, Kyobutungi C. The evolution of noncommunicable diseases policies in post-apartheid South Africa. BMC Public Health. 2018;15:18

22. Ndinda C, Hongoro C. Analysis of non-communicable disease prevention policies in Africa: a case study of South Africa. Afr Popul Health Res Cent. 2017.

23. Stacey N, Mudara C, Ng SW, van Walbeek C, Hofman K, Edoka I. Sugarbased beverage taxes and beverage prices: evidence from South Africa's health promotion levy. Soc Sci Med. 2019;1:238. https://doi.org/10.1016/j. socscimed.2019.112465.

24. Sports and Recreation South Africa. Big Walk Day 2019. 2019. Available from: https://www.srsa.gov.za/media/national-recreation-daybig-walk-activities

25. Kinsman J, Norris SA, Kahn K, Twine R, Riggle K, Edin K, et al. A model for promoting physical activity among rural south African adolescent girls. Glob Health Action. 2015;8(1):28790. https://doi.org/10.3402/gha.v8.28790.

26. Wentzel-Viljoen E, Steyn K, Lombard C, De Villiers A, Charlton K, Frielinghaus $S$, et al. Evaluation of a mass-media campaign to increase the awareness of the need to reduce discretionary salt use in the south African population. Nutrients. 2017:9(11):1-12. https://doi.org/10.3390/nu9111238.

27. National Council Against Smoking. National Quit Line / National Council against Smoking. 2019. Available from: https://www.againstsmoking.co.za 
28. Cancer National Association of South Africa. CANSA's eKick Butt programme. 2019

29. Smokenders. https://smokenders.com

30. Sports and Recreation South Africa. The promotion of physical activity in older. 2021.

31. Sports and Recreation South Africa. Move for Health Day 2019. 2019. Available from: https://www.srsa.gov.za/media/move-health-day-2019

32. Sports and Recreation South Africa. National Recreation Day 2019. 2019. Available from: https://www.srsa.gov.za/content/national-recreation-day

33. Spires M, Delobelle P, Sanders D, Puoane T. South African Health Review Diet-related non-communicable diseases in South Africa: determinants and policy responses. South Afr Health Rev. 2016;1:35-42.

34. Charlton K, Ware L, Baumgartner J, Cockeran M, Schutte AE, Naidoo N, et al. How will South Africa's mandatory salt reduction policy affect its salt iodisation programme? A cross-sectional analysis from the WHO-SAGE wave 2 salt and tobacco study. BMJ Open. 2018;1, 8(3). https://doi.org/10.1136/ bmjopen-2017-020404.

35. Maredza M, Hofman KJ. A hidden menace: cardiovascular disease in South Africa and the costs of an inadequate policy response. SA Hear. 2017;7(4): 48-57. https://doi.org/10.24170/8-1-1924.

36. Sports and Recreation South Africa. The National Sport and Recreation Strategic Plan 2012. 2012.

37. Hofman K, Lee R. Inter-sectoral case study: Successful sodium regulation in South Africa; 2013.

38. The World Health Organisation. National non -communicable diseases targets for South Africa. 2010

39. Mukanu MM, Zulu JM, Mweemba C, Mutale W. Responding to noncommunicable diseases in Zambia: a policy analysis. Health Res Policy Syst. 2017;15:1-9.

40. Bosu WK. A comprehensive review of the policy and programmatic response to chronic non-communicable disease in Ghana. Ghana Med J. 2012;46(2 Suppl):69-78.

41. Juma PA, Mohamed SF, Matanje Mwagomba BL, Ndinda C, Mapa-Tassou C, Oluwasanu $\mathrm{M}$, et al. Non-communicable disease prevention policy process in five African countries authors. BMC Public Health. 2018;18(Suppl 1):1-2.

42. Bakhtiari A, Takian A, Majdzadeh R, Haghdoost AA. Assessment and prioritization of the WHO "best buys" and other recommended interventions for the prevention and control of non-communicable diseases in Iran. BMC Public Health. 2020;20(1):333. https://doi.org/10.1186/s12889-02 0-8446-X.

43. Biswas T, Pervin S, Tanim MIA, Niessen L, Islam A. Bangladesh policy on prevention and control of non-communicable diseases: a policy analysis. BMC Public Health. 2017;17(1):1-11. https://doi.org/10.1186/s12889-017-44 94-2.

44. de Graft Aikins A, Boynton P, Atanga LL. Developing effective chronic disease interventions in Africa: Insights from Ghana and Cameroon. Global Health. 2010;6:6.

45. Boudreaux C, Noble C, Coates MM, Kelley J, Abanda M, Kintu A, et al. Noncommunicable Disease (NCD) strategic plans in low- and lower-middle income Sub-Saharan Africa: framing and policy response. Glob Health Action. 2020;13(1):1805165.

\section{Publisher's Note}

Springer Nature remains neutral with regard to jurisdictional claims in published maps and institutional affiliations.

\section{Ready to submit your research? Choose BMC and benefit from:}

- fast, convenient online submission

- thorough peer review by experienced researchers in your field

- rapid publication on acceptance

- support for research data, including large and complex data types

- gold Open Access which fosters wider collaboration and increased citations

- maximum visibility for your research: over $100 \mathrm{M}$ website views per year

At BMC, research is always in progress.

Learn more biomedcentral.com/submissions 